\title{
Empathy: An essential tool in any doctor's skillset
}

In our modern, multicultural society it is increasingly important that doctors are competent and empathic. Empathy ensures that doctors are able to make a meaningful contribution to the lives of their patients and protects them against burnout.

Reiss $^{[1]}$ eloquently describes empathy as a critical interpersonal and social quality that 'enables sharing of experiences, needs, and desires between individuals and provides an emotional bridge that promotes pro-social behaviour', and relates the benefits of empathy for doctor and patient. Many fail to realise that empathy can be learnt, and that it is not simply an inherent quality or one that develops in early childhood. During the past 20 years, after the development of functional magnetic resonance imaging (fMRI), there has been significant research in cognitive neuroscience. For example, we now understand that mirror neurones enable one to feel the pain of another person ${ }^{[2]}$ and are responsible for emotional contagion. More recently, we learnt about another area of the brain, the right supramarginal gyrus, ${ }^{[3]}$ which enables humans to recognise and overcome emotional egocentricity when attempting to imagine or understand the perspective of someone else.

It might seem surprising that recognising patients' emotions is key to unlocking more about their condition. It has been demonstrated that empathy and effective communication not only determine patient outcomes, ${ }^{[4]}$ but are more effective in reducing the likelihood of litigation than either theoretical knowledge or technical expertise. ${ }^{[1]}$ During doctor-patient interaction, empathy is the critical element of communication shown to affect both diagnosis and prescription. In the case of a doctor who attempts to understand the feelings, experiences and attitudes of their patients, it leads to a more effective interview and therapeutic agreement, increased adherence ${ }^{[5]}$ and improved patient outcomes. Furthermore, empathy is thought to mitigate against doctor burnout, improve mental health and enhance the sense of connection and well-being derived from working in a helping profession. ${ }^{[4,6]}$

\section{What is clinical empathy?}

Hojat et al..$^{[7]}$ refer to empathy in the doctor-patient relationship as clinical empathy - a concept with affective and cognitive domains. Affective or emotional empathy has an evolutionary function and results from activation of mirror neurones; it is especially relevant when the patient is perceived - consciously or unconsciously as being from the same 'tribe'. To limit over-identification, it is important that affective empathy be balanced with self-awareness and an ability to separate one's emotions from those of the other person. ${ }^{[4]}$ Cognitive empathy allows the doctor to understand the patient's perspective as being different from their own. Realising this difference influences what the patient might be feeling, thinking and experiencing. ${ }^{[4,6]}$ Cognitive empathy is especially important where there is an evolutionary bias away from those with racial, ethnic, religious or physical differences and where affective empathy may not be an automatic response. ${ }^{[1]}$ Cognitive empathy therefore limits emotional contagion and requires self-awareness or mindfulness and emotional intelligence or perspective-taking, which can be taught and developed through practice.

\section{Difference between empathy and sympathy}

Empathy differs from sympathy, as empathy attempts to help the other person and is based on an understanding of the patient's perceived needs and not simply on the doctor's response to those needs. Sympathy is a pity-based response, where the doctor tries to relieve distress when witnessing a patient's suffering. ${ }^{[4,8]}$ Sympathy is seldom helpful, as it does not address the real issues or empower the patient to find relevant solutions. Sympathy stems from lack of a clear distinction between the self and the other, or emotional contagion and over-identification with the patient. It leads to burnout, as the doctor assumes responsibility for ending the patient's suffering, which is not only burdensome but also disrespectful and disempowering for the patient. By contrast, cognitive empathy arises from a recognition of the separateness between doctor and patient perspectives, which facilitates emotional regulation, reduces burnout and allows for a more empowering doctor-patient relationship. ${ }^{[4]}$

\section{Teaching and developing cognitive empathy}

Many people assume that they are either empathic or that they do not possess this quality; they do not believe that empathic communication skills can be taught. Neither of these assumptions is true. Cognitive empathy is learnt and does not change how one feels or thinks, but rather recognises that the way in which one responds to a situation is different to the patient's response. It is about trying to understand these differences and communicating these assumptions to the patient so that treatment plans are appropriate and relevant.

Empathic communication is a necessary and essential skill for doctors, and should be taught in all medical schools. Learning empathic communication skills, as learning any new behaviour, is not invariably easy, and requires concerted effort and practice. Role models are often not readily available; however, with practice and awareness empathic communication soon feels easier and more natural.

The key skills to developing cognitive empathy or perspectivetaking are the same as those required for effective communication in all relationships (Table 1).

Furthermore, it is essential that a person practising cognitive empathy is self-aware and able to differentiate their own emotions from those of the patient by the regular practice of mindfulness. Increased self-awareness must be balanced with self-compassion ${ }^{[9]}$ to foster kindness and understanding towards oneself, rather than harsh self-criticism and judgement.

We would like to argue that clinical empathy, which enables the patient to feel seen and heard, is especially important in the South African context, where doctors and their patients might be consciously and unconsciously biased. ${ }^{[1]}$ Cognitive empathy can be learnt, and carries enormous benefit for doctors and patients. It is not something that just happens; we need to choose to pay attention and to extend ourselves, which requires effort.

Table 1. Empathic communication skills

- Foster a supportive, respectful environment

- Listen actively

- Recognise emotion and non-verbal cues

- Be curious - explore patients' perspectives with open questions

- Allow patients to talk about their feelings, without judgement

- Be aware of your own emotions

- Check understanding and assumptions with the patient 


\section{E Archer, R Turner}

Centre for Health Professions Education, Faculty of Medicine and Health Sciences, Stellenbosch University, Cape Town, South Africa elizea@sun.ac.za

1. Reiss H. The science of empathy. J Patient Experience 2017;4(2):74-77. https://doi.org/10.1177/2374373517699267

2. Singer T, Seymour B, O'Doherty J, Kaube H, Dolan RJ, Frith CD. Empathy for pain involves the affective but not sensory components of pain. Science 2004;303(5661):1157-1162. https://doi. org/10.1126/science. 1093535

3. Silani G, Lamm C, Ruff CC, Singer T. Right supramarginal gyrus is crucial to overcome emotional egocentricity bias in social judgments. J Neurosci 2013;33(39):15466-15476. https://doi.org/10.1523/ egocentricity bias in social

4. Thirioux B, Birault F, Jaafari N. Empathy is a protective factor of burnout in physicians: New Thirioux $\mathrm{B}$, Birault $\mathrm{F}$, Jaafari $\mathrm{N}$. Empathy is a protective factor of burnout in physicians: New
neurophenomenological hypotheses regarding empathy and sympathy in care relationship. Front Psychol 2016;7(763):1-11. https://doi.org/10.3389/fpsyg.2016.00763
5. Hegazi I, Wilson I. Maintaining empathy in medical school: It is possible. Med Teach 2013;35(12):10021008. https://doi.org/10.3109/0142159X.2013.802296

6. Wagaman MA, Geiger JM, Shockley C, Segal EA. The role of empathy in burnout, compassion 6. Wagaman MA, Geiger JM, Shockley C, Segal EA. The role of empathy in burnout, compassion
satisfaction, and secondary traumatic stress among social workers. Soc Work 2015;60(3):201-209. satisfaction, and secondary traumatic stress among social workers. Soc Work 2015;60(3):201-209. https://doi.org/10.1093/sw/swv014

7. Hojat M, Gonnella JS, Nasca TJ, Mangione S, Vegare M, Magee M. Physician empathy: Definition, components, measurement, and relationship to gender and specialty. Am J Psychiat 2002;159(9):15631569. https://doi.org/10.1176/appi.ajp.159.9.1563

8. Sinclair S, Beamer K, Hack TF, et al. Sympathy, empathy, and compassion: A grounded theory study of palliative care patients' understandings, experiences, and preferences. Palliat Med 2017;31(5):437-447. https://doi.org/10.1177/0269216316663499

9. Neff K. Self-compassion: An alternative conceptualization of a healthy attitude toward oneself. Self Ident 2003;2:85-101. https://doi.org/10.1080/15298860390129863

S Afr Med J 2019;109(1):11-12. DOI:10.7196/SAMJ.2019.v109i1.13732 